\title{
Sensitive Voltammetric Determination of Natural Flavonoid Quercetin on a Disposable Graphite Lead
}

\author{
Dai Long Vu', Simona Žabč́ková ${ }^{1}$, Libor Červenka ${ }^{1 *}$, Bensu Ertek ${ }^{2}$ and Yusuf Dilgin ${ }^{2}$ \\ ${ }^{1}$ University of Pardubice, Studentska 573, CZ-53210 Pardubice, Czech Republic \\ ${ }^{2}$ Canakkale Onsekiz Mart University, Mart University 18, TR-17100 Canakkale, Turkey
}

Received: March 18, 2015

Accepted: July 8, 2015

\begin{abstract}
Summary
In this paper, a pencil graphite electrode was pretreated using chronoamperometry technique in phosphate buffer solution $(\mathrm{pH}=7.0)$ for sensitive determination of quercetin. Oxidation of quercetin was investigated using pretreated pencil graphite electrode and anodic stripping differential pulse voltammetry. Under optimal conditions, the anodic current of quercetin exhibited linear response to its concentration in the range from 0.001 to $1.5 \mu \mathrm{mol} / \mathrm{L}$ with the limit of detection of $0.3 \cdot 10^{-3} \mu \mathrm{mol} / \mathrm{L}$. The proposed method was successfully applied for the determination of quercetin in cranberry and blackcurrant juices with recovery rate from 93.2 to $94.7 \%$. Solid-phase extraction was found to be necessary prior to voltammetric determination of quercetin in fruit juice samples using pretreated pencil graphite electrode.
\end{abstract}

Key words: pencil graphite electrode, voltammetry, quercetin, fruit juices

\section{Introduction}

Quercetin is one of the flavonoids of great importance due to its strong antioxidant effect that can be attributed to the high numbers of hydroxyl functional groups and to its conjugated orbitals by which quercetin is able to donate electrons or hydrogens (1). Besides their important biological roles in plant pigmentation, flavonoids possess anticancer, antiviral and anti-inflammatory properties, which are the consequence of their affinity to proteins and their antioxidant properties. They are well known for their antioxidant abilities and hold promise for preventing age-related diseases, including heart disease and cancer $(2,3)$. These health-related effects make the determination of quercetin of great importance. Separation methods predominate as an analytical tool for determination and quantification of flavonoids including liquid chromatography, thin-layer chromatography and electrophoresis (4) together with gas chromatography (5), spectroscopic (6) and electrochemical methods (7). Compared with these methods, electrochemical techniques have some advantages such as high sensitivity, accuracy, simplicity, low costs and the possibility of miniaturisation. Among electroanalytical techniques, voltammetry is the most frequently used for the determination of readily oxidized species in food and pharmaceutical preparations (8). Various kinds of electrode materials, including platinum (9-11), gold (12), glassy carbon (13-18), carbon paste (19-27) or graphene oxide-based (28-30) electrodes, have been successfully used for the study of the electrochemical behaviour of quercetin. Some of them have been proposed for determination of quercetin in real food and beverage samples such as fruits, fruit juices and tea samples (20-31).

Quercetin is well known for its use as a redox mediator in carbon-based electrodes to enhance the electrocatalytic oxidation of some organic compounds such as dopamine (31), tyramine (32) or NADH (33). When compared with other carbon-based electrodes, pencil graphite electrodes have some advantages such as high electrochemical reactivity, commercial availability, good mechanical 
rigidity, disposability, renewability, low cost, low technology and ease of modification. Due to these useful and important characteristics, scientists have focused on the usage of pencil graphite electrodes for phenolic compound analysis (34-37). In this paper, we describe a simple and rapid method for the determination of quercetin using a pretreated pencil graphite electrode.

\section{Materials and Methods}

\section{Reagents and equipment}

All the reagents including quercetin (99.9\% purity) were purchased from Sigma-Aldrich (Prague, Czech Republic). Deionised water was used in this study ( $G \leq 0.055$ $\mu S)$. If necessary, dissolved oxygen was removed from the solutions by purging them with argon for $15 \mathrm{~min}$ (purity 99.99 \%; Linde Technoplyn, Prague, Czech Republic).

A solution of quercetin $\left(10^{-3} \mathrm{~mol} / \mathrm{L}\right)$ was freshly prepared with absolute ethanol and kept in a dark bottle during the experiments. Britton-Robinson buffer (BRB; $0.1 \mathrm{M}$ ) solution was used as supporting electrolyte. A three-electrode system consisting of pencil graphite working electrode, $\mathrm{Ag} / \mathrm{AgCl} / 3.0 \mathrm{M} \mathrm{KCl}$ reference electrode and platinum wire (counter electrode) connected to a potentiostat (PalmSens, Ivium Technologies, Utrecht, The Netherlands) was used for electrochemical measurement. Pencil graphite lead with a diameter of $0.5 \mathrm{~mm}$ was obtained from A. W. Faber Castell, Prague, Czech Republic. A mechanical pencil (Rotring, Hamburg, Germany) was used as a holder for graphite lead in this study. Electrical contact was obtained by wrapping a metallic wire around the metallic part of the holder. For each individual measurement, a new graphite lead (fresh surface) was used with total of $10 \mathrm{~mm}$ of length immersed into the working solution. The term 'disposable' reflects the ability of the graphite lead to be used for one definite voltammetric measurement (regardless of the number of cycles) until the fouling of the lead surface occurs.

\section{The preparation of the pretreated pencil graphite electrode}

Pretreated pencil graphite electrodes were prepared by a chronoamperometric technique described in our previous study (37). The surface of pencil graphite electrode was pretreated by applying a potential of $1.45 \mathrm{~V}$ for $60 \mathrm{~s}$ in the supporting electrolyte $(0.1 \mathrm{~mol} / \mathrm{L}$ of phosphate buffer solution containing $0.1 \mathrm{~mol} / \mathrm{L}$ of $\mathrm{KCl}, \mathrm{pH}=7.0)$. After the pretreatment, the pencil graphite electrodes were used for the determination of quercetin using anodic stripping differential pulse voltammetry (ASDPV; potential range: $0-0.8 \mathrm{~V}$, potential step: $25 \mathrm{mV}$, potential pulse: $25 \mathrm{mV}$, pulse time: $0.05 \mathrm{~s}$, and scan rate: $100 \mathrm{mV} / \mathrm{s}$ ). The effect of $\mathrm{pH}$, accumulation potential and accumulation time were optimised. All of the pencil graphite electrodes were treated directly before each measurement.

\section{Sample preparation}

Blackcurrant and cranberry juices were purchased on the local market and stored at refrigerated temperature prior to analysis. The preparation of the sample consisted of centrifugation at $2650 \times g$ (Nüve, Ankara, Turkey) for 20 min followed by solid-phase extraction of $10 \mathrm{~mL}$ of the supernatant using solid-phase extraction columns Strata ${ }^{\circledR}$ C18-E (55 $\mu \mathrm{m}, 70$ A; Phenomenex, Torrance, CA, USA). The target analyte was collected in $2 \mathrm{~mL}$ of methanol, then $50-\mu \mathrm{L}$ aliquot was added to supporting electrolyte and measured. Any statistical differences were computed using a Student's $t$-test at the probability level $p=0.05$ (OriginPro v. 9; OriginLab Corporation, Northampton, MA, USA).

\section{Results and Discussion}

\section{The effect of pretreatment on the oxidation of quercetin}

The responses of quercetin oxidation on the pretreated and bare pencil graphite electrode obtained using ASDPV technique in a BRB at $\mathrm{pH}=3.0$ were compared. As can be seen in Fig. 1, the oxidation peak was obtained at the potential of $0.375 \mathrm{~V}$ using both pretreated pencil graphite electrode $((24.07 \pm 0.25) \mu \mathrm{A})$ and bare pencil graphite electrode $((10.03 \pm 0.12) \mu \mathrm{A})$ in the presence of 1.2 $\mu \mathrm{mol} / \mathrm{L}$ of quercetin $(\mathrm{p}<0.01)$. Since the highest signal of quercetin oxidation was observed on the pretreated pencil graphite electrode, it was used in further experimental procedures. The oxidation of $3^{\prime}, 4^{\prime}$-dihydroxybenzoic moiety occurs at the potential of $0.375 \mathrm{~V}$, as was confirmed in other studies $(9,13,18,20,27)$.

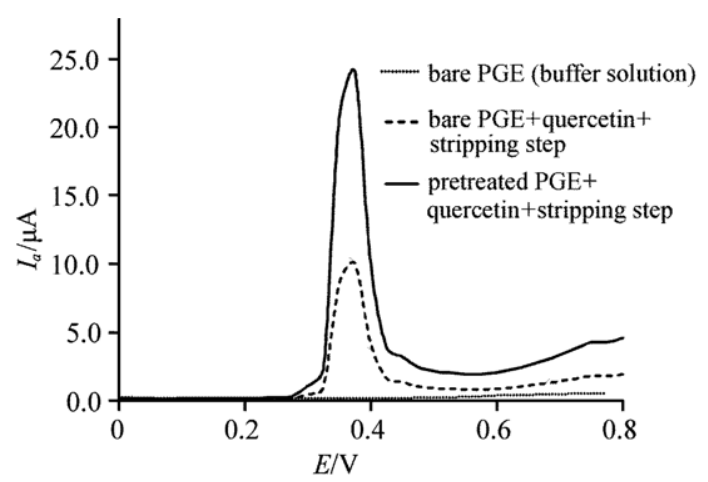

Fig. 1. Anodic stripping differential pulse voltammetry curves of $1.2 \mu \mathrm{mol} / \mathrm{L}$ of quercetin using bare pencil graphite electrode (PGE) and pretreated PGE in Britton-Robinson buffer $(\mathrm{pH}=3.0)$ accumulated at $0.1 \mathrm{~V}$ for $120 \mathrm{~s}$ (potential range from 0.0 to $0.8 \mathrm{~V}$, potential step $25 \mathrm{mV}$, potential pulse $25 \mathrm{mV}$, pulse time $0.05 \mathrm{~s}$ and scan rate $100 \mathrm{mV} / \mathrm{s}$ ). Bare PGE response in buffer solution served as control

\section{The effect of the scan rate on the oxidation of quercetin}

The electrochemical behaviour of pretreated pencil graphite electrode was investigated by recording differential pulse voltammetry in a BRB solution $(\mathrm{pH}=7.0)$ at various scan rates in the presence of $10^{-5} \mathrm{~mol} / \mathrm{L}$ of quercetin. As indicated in Fig. 2, the oxidation currents increased linearly with the scan rate (Fig. 2, inset a), giving the following equation:

$$
I_{\mathrm{a}}=0.012 v+0.059 \quad\left(\mathrm{R}^{2}=0.996\right)
$$

where $I_{\mathrm{a}}$ is the oxidation current $(\mu \mathrm{A}), v$ is the scan rate $(\mathrm{mV} / \mathrm{s})$ and $\mathrm{R}^{2}$ represents the coefficient of determination. 


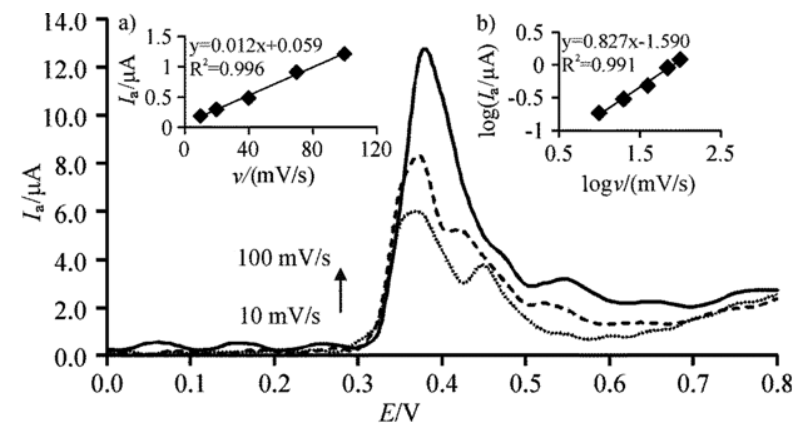

Fig. 2. Differential pulse voltammetry at various scan rates (from 10 to $100 \mathrm{mV} / \mathrm{s}$ ) in the presence of $1.0 \mu \mathrm{mol} / \mathrm{L}$ of quercetin in Britton-Robinson buffer at $\mathrm{pH}=7.0$. Inset: a) the oxidation current of quercetin at various scan rates, b) the plot of $\log I_{\mathrm{a}} v \mathrm{~s}$. $\log v$, where $I_{a}$ is oxidation current $(\mu \mathrm{A})$ and $v$ is the scan rate $(\mathrm{mV} / \mathrm{s})$. Potential range from 0.0 to $0.8 \mathrm{~V}$, potential step $25 \mathrm{mV}$, potential pulse $25 \mathrm{mV}$, pulse time $0.05 \mathrm{~s}$

This finding indicates that the electrochemical process of quercetin on pretreated pencil graphite electrode was surface controlled. Also, a plot of the logarithm of the peak current $(\mu \mathrm{A})$ vs. the logarithm of the scan rate $(\mathrm{mV} / \mathrm{s})$ was examined. This relationship was found to be linear with a slope of 0.827 (Fig. 2, inset b). The value of the slope is close to the theoretical value of 1.0 of the adsorbed compound (38). Moreover, another oxidation peak at $0.450 \mathrm{~V}$ appeared at low scan rates (up to $50 \mathrm{mV} / \mathrm{s}$ ) using both bare and pretreated pencil graphite electrodes (Fig. 2). Sokolová et al. (13) claimed that the second oxidation peak probably belongs to the oxidation product formed at the potential of the first oxidation wave using glassy carbon electrode; however, their experiment was performed under strict anaerobic conditions. On the contrary, Brett and Ghica (9) suggested that the oxidation of the hydroxyl group at position 3 at the ring $C$ gave the second oxidation wave at more positive potential. A very small peak was explained by the formation of an intermolecular hydrogen bond of the hydroxyl group (C-3) with the oxygen at position 4 at ring $\mathrm{C}$. This claim was also supported in a study of structural elucidation of the quercetin degradation products in ethanol-water solution (17).

\section{The effect of some parameters on the determination of quercetin by ASDPV}

The $\mathrm{pH}$, accumulation potential and accumulation time have important effects on the determination of quercetin using ASDPV. As can be seen in Fig. 3, the pH influenced both the oxidation potential and the oxidation current. The oxidation potential shifted in the negative direction with increasing $\mathrm{pH}$ from 2.0 to 7.0 , giving the following equation (Fig. 3, inset):

$$
E_{\mathrm{a}}=-68.571 \cdot \mathrm{pH}+583.570 \quad\left(\mathrm{R}^{2}=0.997\right)
$$

The shifting of the anodic potential with increasing $\mathrm{pH}$ at the rate of $68.6 \mathrm{mV}$ per $\mathrm{pH}$ unit generally supports a reaction mechanism which involves equal number of protons and electrons. Oxidation of quercetin did not appear at $\mathrm{pH} \geq 8.0$. It was found that the oxidation peak currents of quercetin on pretreated pencil graphite electrode gradually increased with the decrease of $\mathrm{pH}$ values, indicating the higher enhancement effect of pretreated pencil

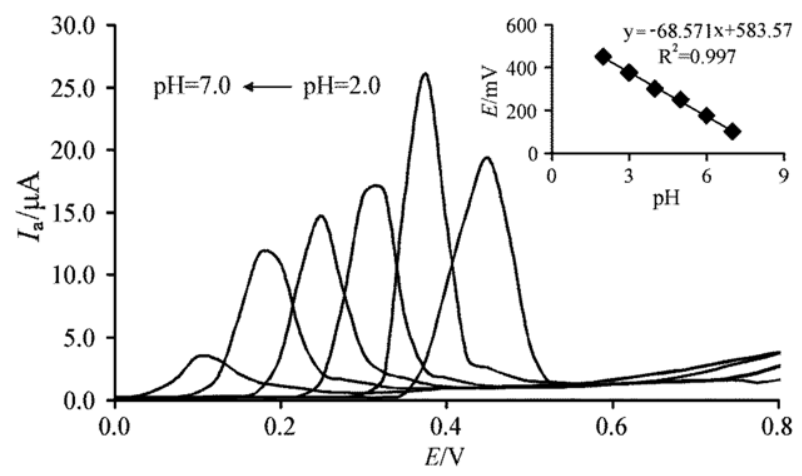

Fig. 3. Anodic stripping differential pulse voltammetry curves of $1.0 \mu \mathrm{mol} / \mathrm{L}$ of quercetin using pretreated pencil graphite electrode at various $\mathrm{pH}$. Accumulation potential $0.1 \mathrm{~V}$, accumulation time $120 \mathrm{~s}$ (potential range from 0.0 to $0.8 \mathrm{~V}$, potential step $25 \mathrm{mV}$, potential pulse $25 \mathrm{mV}$, pulse time $0.05 \mathrm{~s}$ and scan rate $100 \mathrm{mV} / \mathrm{s}$ ). Inset: the effect of $\mathrm{pH}$ on the oxidation potential of quercetin

graphite electrode in more acidic conditions. However, the oxidation current of quercetin decreased after reaching the highest value at $\mathrm{pH}=3.0$. The oxidation current depended on both accumulation potential and accumulation time (data not shown). Therefore, the optimum conditions were chosen as: supporting electrolyte BRB at $\mathrm{pH}=3.0$, accumulation potential of $0.1 \mathrm{~V}$ and accumulation time of $120 \mathrm{~s}$.

The enhancement of the electrochemical activity of pencil graphite electrode towards quercetin can be attributed to the increased formation of oxygen-containing groups, such as carbonyl and carboxyl on the graphite lead surface during the treatment (39). Quercetin as a molecule containing several hydroxyl groups bound to the aromatic rings (Fig. 4) acts as a weak acid.<smiles>O=c1c(O)c(-c2ccc(O)c(O)c2)oc2cc(O)cc(O)c12</smiles>

Fig. 4. The structure of quercetin

The value of $\mathrm{pK}_{1}=5.9$ was reported in the solution under argon atmosphere (40). We assume that specific interactions among oxygen-containing groups at the surface of the electrode and hydroxyl groups of quercetin occurred under acidic conditions. With increasing $\mathrm{pH}$, oxygen-containing groups in pencil lead were deprotonized and anionic forms of quercetin $\left(\mathrm{QH}^{-}\right.$and $\left.\mathrm{Q}^{2-}\right)(13)$ were formed, leading to repulsion of negatively charged quercetin from the negatively charged surface. The same mechanism of interaction between tannic acid and the pretreated pencil graphite electrode was described in our previous study (37).

As can be seen in Fig. 5, the oxidation current of quercetin is proportional to its concentration in the range from 0.001 to $1.5 \mu \mathrm{mol} / \mathrm{L}$ with the calibration curve (Fig. 5, inset) calculated with the following equation: 


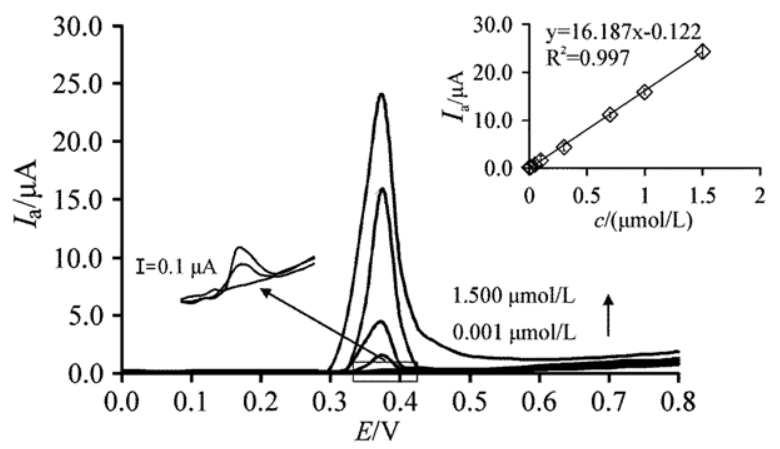

Fig. 5. Anodic stripping differential pulse voltammetry curves of various concentrations (from 0.001 to $1.500 \mu \mathrm{mol} / \mathrm{L}$ ) of quercetin on pretreatment pencil graphite electrode in Britton-Robinson buffer at $\mathrm{pH}=3.0$ after deposition at the potential of $0.1 \mathrm{~V}$ for $120 \mathrm{~s}$. Potential range from 0.0 to $0.8 \mathrm{~V}$, potential step $25 \mathrm{mV}$, potential pulse $25 \mathrm{mV}$, pulse time $0.05 \mathrm{~s}$ and scan rate $100 \mathrm{mV} / \mathrm{s}$. Inset: the plot of oxidation current $v s$. concentration of quercetin

$$
I_{\mathrm{a}}=16.187 c-0.122 \quad\left(\mathrm{R}^{2}=0.997\right)
$$

where $I_{\mathrm{a}}$ is the oxidation current $(\mu \mathrm{A})$ and $c$ is the molar concentration $(\mu \mathrm{mol} / \mathrm{L})$. The limit of detection (LOD) was calculated using the equation:

$$
\mathrm{LOD}=3 \mathrm{~s}_{\mathrm{b}} / m
$$

where $s_{b}$ is the standard deviation of the blank response and $m$ is the slope of the calibration plot of $0.3 \cdot 10^{-3} \mu \mathrm{mol} / \mathrm{L}$. Limit of quantification (LOQ) was $10^{-3} \mu \mathrm{mol} / \mathrm{L}$ (signal to noise ratio of 10 ). The repeatability of the method was investigated by the measurements of 50, 100 and 1200 nmol/L of quercetin $(N=15)$ and the relative standard deviation (RSD) was found to be 3.9, 4.2 and $4.5 \%$, respectively. The linearity ranges and calculated LOD obtained from the pretreated pencil graphite electrode were compared with other methods. As can be seen in Table 1, two papers proposed methods for the determination of quercetin with LOD close to $\mu \mathrm{mol} / \mathrm{L}$ using modified graphene oxide as an electrode material $(29,30)$. Although the linear dynamic range was found to be better when using a glassy carbon electrode modified with graphene oxide (29), the preparation of graphene oxide is time-consuming procedure requiring strong oxidative compounds. The broadest working concentration range for determination of quercetin has been obtained in a study of Gupta et al. (24) with ionic liquid carbon paste electrode modified with the nanocomposite mixture of carbon nanotubes and nickel oxide. Even though the pencil graphite electrode is very cheap, extremely sensitive, and simple renewable tool for electrochemical determination of quercetin, it offers excellent results referenced in the above-mentioned studies.

\section{Interference studies}

The influence of potentially interfering species on the detection of quercetin was investigated. The criterion used for determining the presence of interference was the peak current change of $5 \%$ or greater at $10^{-6} \mathrm{~mol} / \mathrm{L}$ of

\begin{tabular}{|c|c|c|c|}
\hline \multirow{2}{*}{ Electrode } & \multirow{2}{*}{$\frac{c(\text { linear dynamic range })}{\mu \mathrm{mol} / \mathrm{L}}$} & \multirow{2}{*}{$\frac{c(\text { limit of detection })}{\mu \mathrm{mol} / \mathrm{L}}$} & \multirow{2}{*}{ Sample (reference) } \\
\hline & & & \\
\hline $\mathrm{Au} / \mathrm{MPA} / \mathrm{CSH}$ & $0.5-12.2$ & n.d. & n.d. (12) \\
\hline Pt-PDA@SiO $2 /$ GCE & $0.05-0.383$ & 0.016 & tea, apple, onion (17) \\
\hline PVP-CPV & $0.5-5.5$ & 0.17 & pharmaceutical (19) \\
\hline CNTPE & $0.1-1.0$ & 0.03 & blood serum (20) \\
\hline Nafion/MWCNT/GPE & $10.0-910.0$ & $6.0 / 5.7$ & dry/frozen fruit (21) \\
\hline $\mathrm{Ac}-\mathrm{Si} / \mathrm{CPE}$ & $5.0-100.0^{*}$ & $* 3.53$ & tea $(22)$ \\
\hline CNTPE-Cu & n.d. & 0.543 & apple juice (23) \\
\hline ILs/NiO/CNT/CPE & $0.08-400$ & 0.03 & onion, apple (24) \\
\hline DNA-CPE & n.d. & 0.0385 & n.d. (25) \\
\hline CPE/alumina & n.d. & 0.001 & tea $(26)$ \\
\hline $\mathrm{MIP} / \mathrm{GO} / \mathrm{GC}$ & $0.60-15.0$ & 0.048 & fruit juices (28) \\
\hline GCE/GO & $0.006-10.000$ & 0.0036 & onion, apple (29) \\
\hline AgNPs-AETGO & $0.01-5.00$ & 0.003 & grape wine (30) \\
\hline p-AMT/PGE & $0.1-6.0^{*}$ & 2.2 & n.d. (35) \\
\hline Pre-PGE & $0.001-1.5$ & 0.0003 & fruit juices (this study) \\
\hline
\end{tabular}

Table 1. Comparison of the efficiency of some modified electrodes used in the electrocatalysis of quercetin in real samples

$\mathrm{Au} / \mathrm{MPA} / \mathrm{CSH}=$ gold electrode modified with 3-mercaptopropionic acid/L-cystein, $\mathrm{Pt}-\mathrm{PDA} @ \mathrm{SiO}_{2} / \mathrm{GCE}=$ glassy carbon electrode modified with platinum-polydopamine-coated silica nanocomposite, $\mathrm{PVP}-\mathrm{CPV}=$ poly(vinylpyrrolidone)-modified carbon paste electrode, CNTPE=carbon nanotube-nujol paste electrode, Nafion/MWCNT/GPE=multiwalled carbon nanotube graphite paste electrode, $\mathrm{Ac}-\mathrm{Si} / \mathrm{CPE}=$ activated silica-gel carbon paste electrode, $\mathrm{CNTPE} / \mathrm{Cu}=$ carbon nanotube paste electrode modified with copper nanoparticles, $\mathrm{ILs} / \mathrm{NiO} / \mathrm{CNT} / \mathrm{CPE}=\mathrm{NiO}$ carbon nanotube nanocomposite modified ionic liquid carbon paste electrode, $\mathrm{DNA}-\mathrm{CPE}=$ carbon paste electrode modified with DNA, CPE/alumina=carbon paste electrode modified with alumina microfibres, MIP/GO/GC= molecularly imprinted polymer-incorporated graphene oxide-modified electrode with polypyrrole, GCE/GO=graphene oxide-modified glassy carbon electrode, AgNPs-AETGO=2-aminoethanethiol functionalized graphene oxide with silver nanoparticles, p-AMT/ PGE=polymerized 5-amino-2-mercapto-1,3,4-thiadiazole pencil graphite electrode, Pre-PGE=pretreated pencil graphite electrode; n.d.=not determined; ${ }^{*}$ originally expressed in $\mu \mathrm{g} / \mathrm{L}$ 
quercetin. It was found that 200 -fold increase of concentration of $\mathrm{K}^{+}$and $\mathrm{Na}^{+}$, 100 -fold of glucose, 80 -fold of tartaric acid, 70-fold of rutin, 60-fold of oxalic acid, 50-fold of citric acid, 40-fold of $\mathrm{Ca}^{2+}, \mathrm{Mg}^{2+}$ and $\mathrm{Ni}^{2+}, 30$-fold of ascorbic acid and $\mathrm{Cr}^{3+}, 25$-fold of $\mathrm{Fe}^{3+}$ and $\mathrm{Zn}^{2+}$ and 15-fold of $\mathrm{Cd}^{2+}$ and $\mathrm{Cu}^{2+}$ did not interfere with the analysis of quercetin using pretreated pencil graphite electrode.

\section{Analytical application}

The proposed method was applied to determine the presence of quercetin in cranberry and blackcurrant juices with the results shown in Table 2.

Table 2. Determination of quercetin in fruit juice samples and the recovery data $(N=8)$

\begin{tabular}{|c|c|c|c|}
\hline \multirow{2}{*}{ Sample } & $c$ (spiked) & $c$ (found) & Recovery \\
\hline & $\mathrm{mg} / \mathrm{L}$ & $\mathrm{mg} / \mathrm{L}$ & $\%$ \\
\hline \multirow{2}{*}{ Cranberry } & 0.00 & $0.59 \pm 0.11$ & n.d. \\
\hline & 0.34 & $0.92 \pm 0.08$ & 94.72 \\
\hline \multirow{2}{*}{ Blackcurrant } & 0.00 & $0.16 \pm 0.05$ & n.d. \\
\hline & 0.34 & $0.48 \pm 0.10$ & 93.24 \\
\hline
\end{tabular}

n.d.=not determined

It was necessary to include cleaning steps because of the solid contents in both samples. The presence of colourful antocyanins in cranberry and blackcurrant juices significantly increased the background currents, thus decreasing the sensitivity of the pretreated pencil graphite electrode in this study (data not shown). The solid-phase extraction procedure successfully cleaned the sample from antocyanins and allowed to determine the presence of quercetin with a good recovery in the range of $93.24-94.72 \%$.

\section{Conclusions}

In this study the electrochemical determination of quercetin on the surface of pretreated pencil graphite electrode by anodic stripping differential pulse voltammetry has been investigated for the first time. It was shown that the pretreatment procedure remarkably enhanced the oxidation peak current of quercetin compared with that using bare pencil graphite electrode. Under optimal conditions, the anodic peak current is linearly proportional to the concentration of quercetin at a wide concentration range and at very low limit of detection in comparison with other studies. The electrode is proved to be of high sensitivity and reproducibility. The working electrode used in this study can be purchased in local market at the minimum cost and requires minor modification in phosphate buffer to be an excellent tool for voltammetric determination of quercetin. The method was successfully applied to the fruit juices; however, the cleaning and extraction steps are necessary for good recovery.

\section{References}

1. Biesaga M, Pyrzynska K. Analytical procedures for determination of quercetin and its glycosides in plant material. Crit Rev Anal Chem. 2009;39:95-107.

http://dx.doi.org/10.1080/10408340902820718
2. Islam MA, Schmidt RW, Gunaseelan S, Sanches A. An update on the cardiovascular effects of quercetin, a plant flavanoid. Curr Nutr Food Sci. 2014;10:36-48. http://dx.doi.org/10.2174/157340131001140328115216

3. Thennarasu A. Quercetin in health and disease. Res J Pharm Technol. 2013;6:1397-9.

4. Dmitrienko SG, Kudrinskaya VA, Apyari VV. Methods of extraction, preconcentration, and determination of quercetin. J Anal Chem. 2012;67:340-53. http://dx.doi.org/10.1134/S106193481204003X

5. Nolvachai Y, Marriott PJ. GC for flavonoids analysis: past, current and prospective trends. J Sep Sci. 2013;36:20-36. http://dx.doi.org/10.1002/jssc.201200846

6. Martelo-Vidal MJ, Vázquez M. Determination of polyphenolic compounds of red wines by UV-VIS-NIR spectroscopy and chemometrics tools. Anal Methods. 2014;158:28-34. http://dx.doi.org/10.1016/j.foodchem.2014.02.080

7. Gil ES, Couto RO. Flavonoid electrochemistry: a review on the electroanalytical applications. Braz J Pharmacog. 2013;23: 542-58. http://dx.doi.org/10.1590.S0102-695X2013005000031

8. Gupta VK, Jain R, Radhapyari K, Jadon N, Agarwal S. Voltammetric techniques for the assay of phamaceuticals - a review. Anal Biochem. 2011;408:179-96. http://dx.doi.org/10.1016/j.ab.2010.09.027

9. Brett AMO, Ghica ME. Electrochemical oxidation of quercetin. Electroanalysis. 2003;15:1745-50. http://dx.doi.org/10.1002/elan.200302800

10. Andreescu S, Andreescu D, Sadik OA. A new electrocatalytic mechanism for the oxidation of phenols at platinum electrodes. Electrochem Comm. 2003;5:681-8. http://dx.doi.org/10.1016/S1388-2481(03)00166-8

11. Pierozynski B, Zielinska D. Electrooxidation of quercetin at polycrystalline Pt electrode. Int J Electrochem Sci. 2010;5: 1507-15.

12. de Oliveira FCM, Serrano SHP. Electrochemically active L-cysteine gold modified electrodes. Electrochem Acta. 2014; 125:566-72.

http://dx.doi.org/10.1016/j.electacta.2014.01.079

13. Sokolová R, Ramešová Š, Degano I, Hromadová M, Gál M, Žabka J. The oxidation of natural flavonoid quercetin. Chem Comm. 2012;48:3433-5. http://dx.doi.org/10.1039/C2CC18018A

14. Fu Y, Lin Y, Chen T, Wang L. Study on the polyfurfural film modified glassy carbon electrode and its application in polyphenols determination. J Electroanal Chem. 2012;687:25-9. http://dx.doi.org/10.1016/j.jelechem.2012.09.040

15. Jin JH, Kwon C, Park W, Kim S, Jung S. Electrochemical characterization of a glassy carbon electrode modified with microbial succinoglycan monomers and multi-wall carbon nanotubes for the detection of quercetin in an aqueous electrolyte. J Electroanal Chem. 2008;623:142-6. http://dx.doi.org/10.1016/j.jelechem.2008.07.002

16. Medvidović-Kosanović M, Šeruga M, Jakobek L, Novak I. Electrochemical and antioxidant properties of (+)-catechin, quercetin and rutin. Croat Chem Acta. 2010;83:197-207.

17. Manokaran J, Muruganantham R, Muthukrishnaraj A, Balasubramanian N. Platinum-polydopamine $@ \mathrm{SiO}_{2}$ nanocomposite modified electrode for the electrochemical determination of quercetin. Electrochim Acta. 2015;168:16-24. http://dx.doi.org/10.1016/j.electacta.2015.04.016

18. Zhou A, Kikandi S, Sadik OA. Electrochemical degradation of quercetin: isolation and structural elucidation of the degradation products. Electrochem Comm. 2007;9:2246-55. http://dx.doi.org/10.1016/j.elecom.2007.06.026

19. Piovesan JV, Spinelli A. Determination of quercetin in a pharmaceutical sample by square-wave voltammetry using 
a poly(vinylpyrrolidone)-modified carbon-paste electrode. J Braz Chem Soc. 2014;25:517-25. http://dx.doi.org/10.5935/0103-5053.20140019

20. He JB, Lin XQ, Pan J. Multi-wall carbon nanotube paste electrode for adsorptive stripping determination of quercetin: a comparison with graphite paste electrode via voltammetry and chronopotentiometry. Electroanalysis. 2005;17: 1681-6. http://dx.doi.org/10.1002/elan.200503274

21. Zhu QG, Sujari ANA, Ghani SA. Nafion-MWCNT composite modified graphite paste for the analysis of quercetin in fruits of Acanthopanax sessiliflorus. Sensor Actuat B: Chem. 2013; 177:103-10. http://dx.doi.org/10.1016/j.snb.2012.10.112

22. Chen X, Li Q, Yu S, Lin B, Wu K. Activated silica gel based carbon paste electrodes exhibit signal enhancement for quercetin. Electrochim Acta. 2012;81:106-11. http://dx.doi.org/10.1016/j.electacta.2012.07.063

23. Oliveira AC, Mascaro LH. Evaluation of carbon nanotube paste electrode modified with copper nanoparticles and its application to determination of quercetin. Int J Electrochem Sci. 2011;6:804-18.

24. Gupta VK, Golestani F, Ahamdzadeh S, Karimi-Maleh H, Fazli G, Khosravi S. NiO/CNTs nanocomposite modified ionic liquid carbon paste electrode as a voltammetric sensor for determination of quercetin. Int J Electrochem Sci. 2015; 10:3657-67.

25. Satpati AK, Sahoo S, Dey MK, Reddy AVR, Mukhurjee T. Electrochemical and spectroelectrochemical investigations of quercetin on unmodified and DNA-modified carbon paste electrode and its determination using voltammetry. Anal Methods. 2011;3:1344-50. http://dx.doi.org/10.1039/clay05026e

26. Li Y, Huang W. Electrode modified with porous alumina microfibres as a highly sensitive electrochemical sensor for quercetin. Anal Methods. 2015;7:2537-41. http://dx.doi.org./10.1039/c5ay00206k

27. Xiao P, Zhao F, Zeng B. Voltammetric determination of quercetin at a multi-walled carbon nanotubes paste electrode. Microchem J. 2007;85:244-9. http://dx.doi.org/10.1016/j.microc.2006.06.004

28. Sun S, Zhang M, Li Y, He X. A molecularly imprinted polymer with incorporated graphene oxide for electrochemical detection of quercetin. Sensors. 2013;13:5493-506. http://dx.doi.org/10.3390/s130505493

29. Arvand M, Anvari M. A graphene-based electrochemical sensor for sensitive detection of quercetin in foods. J Iran Chem Soc. 2013;10:841-9. http://dx.doi.org/10.1007/s13738-013-0219-3

30. Yola ML, Gupta VK, Eren T, Şen AE, Atar N. A novel electro analytical nanosensor based on graphene oxide/silver nano- particles for simultaneous determination of quercetin and morin. Electrochim Acta. 2014;120:204-11. http://dx.doi.org/10.1016/j.electacta.2013.12.086

31. Chen PY, Vittal R, Nien PC, Ho KC. Enhancing dopamine detection using a glassy carbon electrode modified with MWCNTs, quercetin, and nafion. Biosens Bioelectron. 2009;24:3504-9. http://dx.doi.org/10.1016/j.bios.2009.05.003

32. Raoof JB, Ojani R, Amiri-Aref M, Baghayeri M. Electrodeposition of quercetin at a multi-walled carbon nanotubes modified glassy carbon electrode as a novel and efficient voltammetric sensor for simultaneous determination of levodopa, uric acid and tyramine. Sensor Actuat B: Chem. 2012;166167:508-18.

http://dx.doi.org/10.1016/j.snb.2012.02.096

33. Dilgin Y, Kızılkaya B, Dilgin DG, Gokcel HI, Gorton L. Electrocatalytic oxidation of NADH using a pencil graphite electrode modified with quercetin. Colloid Surface B. 2013;102:816-21.

http://dx.doi.org/10.1016/j.colsurfb.2012.09.030

34. Buratti S, Scampicchio M, Giovanelli G, Mannino S. A lowcost and low-tech electrochemical flow system for the evaluation of total phenolic content and antioxidant power of tea infusions. Talanta. 2008;75:312-6. http://dx.doi.org/10.1016/j.talanta.2007.11.014

35. Muti M, Gençdă̆ K, Nacak FM, Aslan A. Electrochemical polymerized 5-amino-2-mercapto-1,3,4-thiadiazole modified single use sensors for detection of quercetin. Colloid Surface B. 2013;106:181-6. http://dx.doi.org/10.1016/j.colsurfb.2013.01.018

36. Gong ZQ, Sujari ANA, Ab Ghani S. Electrochemical fabrication, characterization and application of carboxylic multiwalled carbon nanotube modified composite pencil graphite electrode. Electrochim Acta. 2012;65:257-65. http://dx.doi.org/10.1016/j.electacta.2012.01.057

37. Vu DI, Ertek B, Dilgin Y, Èervenka L. Voltammetric determination of tannic acid in beverages using pencil graphite electrode. Czech J Food Sci. 2015;33:72-6. http://dx.doi.org/10.17221/221/2014-CJFS

38. Öztürk F, Taşdemir IH, Erdoğan DA, Erk N, Kiliç E. A new voltammetric method for the determination of lercanidipine in biological samples. Acta Chim Slov. 2011;58:830-9.

39. Alipour E, Majidi MR, Saadatirad A, Golabi SM, Alizadeh AM. Simultaneous determination of dopamine and uric acid in biological samples on the pretreated pencil graphite electrode. Electrochim Acta. 2013;91:36-42. http://dx.doi.org/10.1016/j.electacta.2012.12.079

40. Ramešová Š, Sokolová R, Degano I, Bulíčková J, Žabka J, Gál M. On the stability of the bioactive flavonoids quercetin and luteolin under oxygen-free conditions. Anal Bioanal Chem. 2012;402:975-82.

http://dx.doi.org/ 10.1007/s00216-011-5504-3 